\title{
Editorial
}

Rev Estomatol Herediana. 2015 Abr-Jun;25(2):85-86.

\section{Equidad y salud bucal}

\author{
Equity and oral health
}

Carlos García-Zavaleta ${ }^{1,2}$

América Latina y el Caribe conforman la región del mundo que presenta la mayor inequidad social y graves desigualdades en las condiciones de salud y de acceso a los servicios de salud. El incremento de esta brecha entre grupos sociales y las regiones geográficas ha impulsado una mayor preocupación de los organismos internacionales y los gobiernos por las desigualdades en salud y las inequidades, considerándolas entre las emergencias que comprometen el futuro de la humanidad (1).

Las desigualdades en salud reflejan las diferencias entre grupos, con independencia de cualquier posible valoración sobre la justicia de éstas. Las inequidades se refieren al conjunto de desigualdades que se consideran injustas. Las nociones de igualdad y equidad se articulan, con una visión de la salud como derecho humano. Así, la igualdad aparece como el fin y la equidad como un medio. La igualdad se asocia con principios de no discriminación en cuanto al ejercicio de derechos, referidos en este caso particular a la salud y sus determinantes y a la participación en el desarrollo de la salud. La equidad, por su parte, se basa en principios de justicia social y se refiere a las intervenciones dirigidas a eliminar disparidades sistemáticas, injustas y evitables entre grupos sociales respecto al nivel de salud, al acceso a recursos necesarios para su promoción, recuperación y mantenimiento y a la participación en los procesos de desarrollo de la salud $(1,2)$.

Diversos autores y organismos internacionales al analizar las desigualdades e inequidades en salud bucal en el contexto mundial reconocen diversas manifestaciones, tales como: a menor nivel de desarrollo cultural y económico, mayores son los niveles de patologías bucales; que el acceso a la prevención en salud bucal está claramente desequilibrado a favor de los que se encuentran en una posición económica y cultural más favorecida, llegándose a la paradoja de ofrecer prevención a los que más medios tienen y tratamientos generalmente agresivos (exodoncias) a los que menos tienen; que los recursos humanos para salud bucal se encuentran distribuidos desigualmente, observándose altas concentraciones de personal en las ciudades de mayor desarrollo económico y social; un modelo hegemónico de práctica odontológica que responde a un enfoque liberal de mercado y a los intereses de las industrias biotecnológicas alejándose de su verdadero rol social (2-5).La comunidad internacional está impulsando procesos técnicos, políticos y sociales con el propósito de revertir esta situación.

La Organización Mundial de la Salud (OMS), la International Association for Dental Research (IADR) y la Comisión Científica de la Federation Dental International (FDI) han considerado la reducción de las disparidades

Presidente - Asociación Peruana de Odontología Preventiva y Social. Lima, Perú.

Coordinador - Mesa Temática de Salud Bucal - FOROSALUD. Lima, Perú. 
de salud bucal entre los diferentes grupos socioeconómicos de cada país y las desigualdades en la salud bucal de todos los países, como parte de las metas globales para la salud bucal 2020 (6).

La declaración de la Carta de Brasilia sobre la salud bucal de las Américas, de octubre de 2009, reconoce los altos niveles de inequidad social en la distribución de las enfermedades bucales, su impacto en el desarrollo social y económico de nuestros pueblos y el compromiso de aportar a los Objetivos de Desarrollo del Milenio y la necesidad del estricto cumplimiento del deber de los Estados, con la garantía del derecho a la salud bucal con equidad e inclusión social (7).

La creación de la Comisión de los Determinantes Sociales de la Salud en el año 2005, y el señalamiento de la OMS en relación a la Atención Primaria de Salud como "más necesaria que nunca", así como las relaciones iniciadas con el Movimiento Salud de los Pueblos (MSP) sugieren procesos políticos en el orden mundial hacia la búsqueda de la equidad en salud en el marco del desarrollo social. La profesión odontológica no puede permanecer ajena a este proceso y deberá participar activamente del mismo $(2,3)$.

El reto ético más importante para la profesión odontológica hoy en día, es posicionarse políticamente como profesión de la salud comprometida con un fin social o continuar como práctica que depende de las leyes del mercado $(2,3)$.

\section{REFERENCIAS BIBLIOGRÁFICAS}

1. Linares N, Oliva López O. La equidad en salud: propuestas conceptuales, aspectos críticos $\mathrm{y}$ perspectivas desde el campo de la salud colectiva. Medicina Social. 2008; 3(3):247-9.

2. Colegio Oficial de Odontólogos y Estomatólogos de Madrid 1ra región (España). Estudio y análisis de la equidad en salud. Una visión en salud oral. Madrid: Editorial de la Fundación del Colegio de Odontólogos y Estomatólogos de Madrid (FCOEM); marzo 2013.

3. Abadía C. Pobreza y desigualdades sociales: un debate obligatorio en salud oral. Acta Bioethica. 2006; 12 (1):9-22.
4. García I, Tabak L. Global Oral Health Inequalities: The View from a Research Funder. Adv Dent Res. 23(2) 207-10.

5. FDI. Visión 2020 de la FDI. Delinear el futuro de la salud bucodental. 2011.

6. FDI. Declaración de Principios de la FDI. Declaración conjunta de la FDI - OMS - IADR. Objetivos Globales de Salud Bucodental para el año 2020. Aprobada por la Asamblea General de la FDI. Sidney-Australia, 2003.

7. Carta de Brasilia sobre Salud Bucal en las Américas. En: II Encuentro Internacional de Coordinadores Nacionales de Salud Bucal de los Países Latinoamericanos, Brasilia, 2009. 